\title{
MULHERES NEGRAS: UMA TRAJETÓRIA DE CRIATIVIDADE, DETERMINAÇÃO E ORGANIZAÇÃO
}

\author{
MATILDE RIBEIRO
}

Núcleo de Estudos e Pesquisas sobre Movimentos Sociais - Nemos (PUC/SP)

Resumo: Este artigo busca fazer um breve registro focando o processo organizativo das mulheres negras em diálogo com: a inclusão de gênero e raça nas políticas públicas; a realização das conferências internacionais - em especial a Conferência Mundial sobre as Mulheres e a III Conferência Mundial contra o Racismo, a Discriminação Racial, a Xenofobia e as Formas Conexas de Intolerância; o pós-Durban, a ação e o monitoramento; e os 120 anos após a abolição da escravidão. Ao final, são formulados alguns desafios a considerar na luta pela igualdade e justiça social.

Palavras-chave: mulheres negras; movimento feminista; Movimento Negro; organização de mulheres negras.

\section{Breve introdução}

Querem que a gente saiba que eles foram senhores

É nos fomos escravos Eu disse fomos. ${ }^{1}$

Como "Transmissão", em 1988, a sociedade brasileira foi marcada por importantes debates provocados pela elaboração da Constituição Federal (a Constituição Cidadã) ${ }^{2}$ e pelas atividades alusivas aos 100 anos da Abolição da Escravidão. Após 20 anos (2008),

\footnotetext{
Copyright (c) 2008 by Revista Estudos Feministas.

1 O poema "Transmissão" foi escrito por Oliveira Silveira (1941-2009), já mencionado na apresentação deste dossiê. As homenagens feitas em vida, como, por exemplo, o convite para sua participação como expressão de notório conhecimento no Conselho Nacional de Promoção da Igualdade Racial - CNPIR pela presença assídua na construção do Dia Nacional da Consciência Negra, em 20 de novembro, seguem agora após sua partida (OUTUBRO, 2009).

${ }^{2}$ Nesta constituição a cidadania e a dignidade da pessoa humana são princípios estruturantes do Estado Democrático e de Direitos, proclamando-se a promoção do bem de todos "sem preconceitos de origem, raça, sexo, cor, idade e quaisquer outras formas de discriminação" (BRASIL, 1988).
} 
retomam-se os debates e as movimentações em torno desses dois fatos - os 20 anos da Constituição Cidadã trouxeram inúmeras comemorações; os 120 anos da Abolição da Escravidão, como não poderia deixar de ser, trazem controvérsias entre as comemorações e as contestações.

Isso é reflexo de uma sociedade que avança em garantia de direitos, mas que se mantém descompensada pela continuidade de regimes excludentes, como o racismo e o machismo. Obtivemos avanços na agenda política? Sim, muitos!! Porém, não o suficiente para destruir as mazelas deixadas pela escravidão e pela abolição inacabada. Com isso, surgem novas perguntas, indagações e proposições, sobretudo no que diz respeito à busca de visibilidade político-social e melhores condições de vida para mais da metade da população - os negros.

Sem dúvida, a partir da ałuação do movimento social, importantes passos foram dados, resultando na ampliação da participação política da população negra. Em especial, as mulheres negras, demonstraram grande impulso organizativo se tomarmos como referência, também, o ano de 1988, quando no Brasil foi realizado o I Encontro Nacional de Mulheres Negras - I ENMN, no qual verificamos a demarcação de um novo ritmo às formulações políticas e à inserção desse e dos demais setores discriminados na agenda social e política, em âmbito nacional e internacional.

Constata-se esse impulso no processo de organização da V Conferência Mundial sobre as Mulheres (China/Beijing, em 1995) e da III Conferência Mundial contra o Racismo, a Discriminação Racial, a Xenofobia e as Formas Conexas de Intolerância (África do Sul/ Durban, em 2001). Isto é apontado em dois dossiês da Revista Estudos Feministas - "Mulheres Negras" (coordenado por Matilde Ribeiro, em 1995) e "III Conferência Mundial contra o Racismo" (coordenado por Luiza Bairros, em 2002). As coordenadoras dos dossiês argumentam que é impossivel analisar a condição e/ou organização das mulheres em âmbito mundial sem o reconhecimento da positiva movimentação das mulheres negras no Brasil e na America Latina e no Caribe e das contribuições para as conferências de Beijing e de Durban.

Considerando esse cenário, este artigo se propõe a um breve registro da produção social, política e acadêmica, no campo da participação social, partindo das questões de gênero e raça e em particular das mulheres negras.

\section{As mulheres negras e seu processo organizativo}

Filho de branca babujou teu seio/negrinho berrou e berrou, sinhá nenhuma amamentou.

Por que não existe mãe-branca? "Mãe branca?/ora já se viu/é muito desaforo!

As mulheres negras em seu processo político entenderam que não nasceram para perpetuar a imagem da "mãe preta", fizeram desaforos. Entenderam que desigualdades são construídas historicamente, a partir de diferentes padrões de hierarquização constituídos pelas relações de gênero e raça, ${ }^{4}$ que, mediadas pela classe social, produzem profundas exclusões. São combinações de discriminações que geram exclusões, tendo como explicação a perpetuação do racismo e do machismo. Segundo o livro Lugar de negro, de

\footnotetext{
${ }^{3}$ OLIVEIRA SILVEIRA apud Paulo COLIMA, 1982.

${ }^{4}$ Gênero e raça são construções sociais, que resultam quase que invariavelmente em transformação de diferenças em desigualdades. Vale reafirmar que: raça não é uma categoria natural ou biológica; enquanto sexo sim traduz o ser homem ou mulher com suas diferenças biológicas.
} 
Lélia Gonzalez e Carlos Hasembalg, ${ }^{5}$ os espaços destinados à população negra são os de subcidadania. Dessa maneira, passa a existir uma ordem incontestável, homem branco, mulher branca, homem negro, mulher negra.

O estudo Retrato das desigualdades - gênero e raça, realizado em 2007 pelo Instituto de Pesquisa Econômica Aplicada - Ipea, pelo Fundo de Desenvolvimento das Nações Unidas para a Mulher " Unifem e pela Secretaria Especial de Políticas para as Mulheres - SPM, traz informações sobre a posição na ocupação:

Enquanto as mulheres estão mais representadas no trabalho doméstico ${ }^{6}$ e na produção para próprio consumo e trabalho não remunerado, os homens ocupam mais postos com carteira de trabalho assinada e de empregador. [...] Destaca-se, ainda, a alta proporção de jovens negras, com idade entre 16 e 29 anos, que são empregadas domésticas - no caso destas faixas etárias, alcançam o dobro da proporção das jovens brancas. No que diz respeito ao número de trabalhadoras domésticas com carteira de trabalho assinada, percebe-se um relativo aumento na porcentagem ao longo da década: em 1996 verificava-se 18,7\% para as negras e 23,6\% para as brancas; já em 2006 os números passaram a $23,9 \%$ e $30,2 \%$, respectivamente.

Essas situações reproduzidas historicamente impulsionam o movimento feminista em busca de tratamento das questões vinculadas à vida privada como aspectos políticos, demonstrando a complexidade das relações sociais (como sexualidade, violência de gênero, trabalho doméstico etc.). Na luta por direitos, as mulheres buscam romper com a indiferença em torno de questões cotidianas trazendo-as como demandas para a esfera pública.

Um exemplo de ação é a Campanha dos 16 dias de Ativismo pelo Fim da Violência contra as Mulheres como uma iniciativa internacional do Centro para a Liderança Global das Mulheres - Center for Women's Global Leadership liderada no Brasil pelas Ações em Gênero, Cidadania e Desenvolvimento-Agende, com o apoio do Comitê Latino-Americano e do Caribe para a Defesa dos Direitos da Mulher - Cladem (Brasil), da Bancada Feminina no Congresso Nacional, do Fundo de Desenvolvimento das Nações Unidas para a Mulher "Unifem e do governo brasileiro. No Brasil, desde 2003, sob o slogan "Uma vida sem violência é um direito das mulheres", essa campanha aglutina diversos setores sociais e provoca uma extensa agenda de debates na perspectiva da igualdade de gênero e raça/etnia. Buscam-se como importantes resultados a afirmação da Lei Maria da Penha ${ }^{8}$ e o desenvolvimento de estratégias de combate ao racismo, tendo por base o diálogo sobre o trabalho doméstico.

A Fundação Perseu Abramo desenvolveu a pesquisa A mulher brasileira nos espaços público e privado, que trouxe novos elementos para o debate e aponta caminhos para a superação da exclusão e não visibilidade das mulheres. As mulheres brasileiras anunciaram boas mudanças em relação à percepção de sua condição:

$65 \%$ das entrevistadas avaliam que houve melhora em suas vidas (mulheres de ascendência racial só negra $54 \%$ e de ascendência racial só branca $67 \%$ ), mas $89 \%$

\footnotetext{
${ }^{5}$ Lélia GONZALEZ e Carlos HASEMBALG, 1982.

${ }^{6}$ Em Nota Técnica baseada também na PNAD, de 27 de abril de 2008, a Organização Internacional do Trabalho " OIT informa que o trabalho doméstico conta com 6,6 milhões de pessoas no Brasil, desse total, $93,2 \%$ são mulheres e $6,8 \%$ são homens. O trabalho doméstico representa $16,7 \%$ do total da ocupação feminina, o que corresponde, em termos numéricos, a 6,2 milhões de mulheres. De cada 100 negras trabalhadoras no Brasil, 22 são empregadas domésticas.

7 INSTITUTO DE PESQUISA ECONÔMICA APLICADA, FUNDO DE DESENVOLVIMENTO DAS NAÇÕES UNIDAS PARA A MULHER E SECRETARIA ESPECIAL DE POLÍTICAS PARA AS MULHERES, 2007.

${ }^{8}$ BRASIL, 2006.
} 
ainda detectam o machismo na sociedade (ascendências: só negra $86 \%$ e só branca $88 \%$ ) e $43 \%$ assumem ter sofrido algum tipo de violência sexista (mulheres de ascendência racial só negra $54 \%$ e só branca $33 \%$ ), e isto é perceptível no número de entrevistadas que acreditam que seus direitos sociais não são respeitados. Além disso, $28 \%$ são adeptas do feminismo (total ou parcialmente), sendo $28 \%$ mulheres de ascendência racial só negra e $29 \%$ só branca. Outras $25 \%$ não sabem ou têm dúvidas sobre o que significa feminismo ( $32 \%$ entre as mulheres de ascendência racial só negra e $21 \%$ só branca), o que não impede que opinem e reconheçam os efeitos machistas, pois $89 \%$ souberam detectá-los na sociedade.

Esses são elementos importantes para a produção feminista e anti-racista, que têm desenvolvido crítica sistemática à subjugação das mulheres e dos negros.

O Movimento Negro busca o reconhecimento da ancestralidade africana como um valor positivo. Dessa forma, a luta histórica é por garantia da dignidade e de continuidade de resistência contra a exclusão social, buscando com isso a visibilidade e a participação política das mulheres e dos homens negros.

Uma das principais ações contemporâneas foi realizada em Brasília, em 20 de novembro ${ }^{10}$ de 1995, em parceria com outros setores da sociedade - ${ }^{11}$ a Marcha Zumbi dos Palmares contra o Racismo, pela Cidadania e pela Vida, que reuniu cerca de 30 mil manifestantes. Em ato oficial, por meio da coordenação da Marcha, foi entregue ao Presidente da República, Fernando Henrique Cardoso, o Programa de Superação do Racismo e da Desigualdade Racial, o qual apresentava uma série de reivindicações visando à inclusão da população negra nas políticas públicas, com destaque para o mercado de trabalho, a educação, a cultura e a comunicação, a saúde, o combate à violência, a religião e a terra. ${ }^{12}$

Em continuidade, em 2005, realiza-se a II Marcha Zumbi dos Palmares contra o Racismo, pela Cidadania e pela Vida, em Brasília. Conhecido como "Marcha Zumbi + 10", o evento teve duas versões: a mobilização do dia 16 de novembro de 2005, que enfocou a desigualdade socioeconômica e o baixo orçamento público destinado à população negra; e a manifestação do dia 22 de novembro de 2005, que enfatizou a anistia a João Cândido, o Almirante Negro, ${ }^{13}$ a exclusão social e a necessidade de combate à violência e ao genocídio da população negra (sobretudo dos jovens). Em comum, essas mobilizações tiveram o intuito de apresentar reflexões, críticas e proposições ao Governo Federal para o incremento da política de igualdade racial, demandando a aceleração de medidas para a superação do racismo. ${ }^{14}$

Com isso, desenvolve-se a perspectiva de sedimentação macroestrutural dos princípios da diversidade. Porém, são apresentados desafios no interior dos próprios movimentos. Constata-se que, à medida que são conquistados os protagonismos, aprofundam-se complexidades e dificuldades organizativas e teóricas.

\footnotetext{
${ }^{9}$ Matilde RIBEIRO, 2004.

1020 de novembro refere-se ao Dia Nacional da Consciência Negra, marco construído pelo Movimento Negro em homenagem a Zumbi dos Palmares, líder na Serra da Barriga, em Alagoas/Palmares, na luta pela libertação da população negra do regime de escravidão. Em 1995 completou 300 anos em que Zumbi dos Palmares foi cruelmente assassinado.

${ }^{11}$ Central Única dos Trabalhadores - CUT, Partido dos Trabalhadores - PT, Central de Movimentos Populares CMP, Movimento dos Trabalhadores Rurais Sem Terra - MST, movimento feminista, entre outros.

12 MARCHA..., 1995.

13 João Candido foi líder da Revolta da Chibata, que aconteceu no início do século passado em protesto contra os castigos físicos que eram impostos pela Marinha do Brasil. O objetivo do projeto de anistia é de restaurar os direitos que foram assegurados aos revoltosos.

${ }^{14}$ SECRETARIA ESPECIAL DE POLÍTICAS DE PROMOÇÃO DA IGUALDADE RACIAL, 2007.
} 
As mulheres negras têm elaborado crítica sistemática aos movimentos negro e feminista em relação à invisibilidade e à secundarização das questões específicas. Essa perspectiva foi fortemente apontada no texto $A$ mulher negra na década: a busca da autonomia ${ }^{15}$ como subsídio à Conferência de Beijing; e ainda após a Conferência explicita essas situações de conflito político, trilha novos caminhos e amplia seus horizontes na luta pela igualdade e justiça.

Verifica-se que a afirmação de protagonismos desses grupos invisibilizados, a partir da última década, entrou efetivamente na agenda política, estimulando novos estudos e ações.

Inspirados por todo esse debate, Schuma Schumaher e Érico Vital Brazil resgataram a história das mulheres na vida pública em seus dois estudos que fazem parte do trabalho realizado pela Rede de Desenvolvimento Humano - Redeh, projeto Mulher, 500 anos atrás dos panos. A tônica da diversidade foi ressaltada no Dicionário mulheres do Brasil: "foram índias contra a violência dos colonizadores, negras contra a escravidão, brancas contra os valores patriarcais vigentes, todas lutando pela transformação das regras impostas ao feminino". ${ }^{16}$ Já no livro Mulheres negras do Brasil, ${ }^{17}$ os autores afirmam que a pesquisa significou um profundo mergulho em contundentes silêncios da historiografia brasileira:

Constatamos que a ausência de registros sobre a participação das afro-descendentes na formação e no desenvolvimento do Brasil é gritante. Com exceção dos escritos sobre o sistema escravocrata e, por vezes, uma ou outra alusão ao mito Chica da Silva, não se encontraram muitas outras referências e informações sobre as mulheres negras em nossos museus, currículos escolares, livros didáticos e/ou narrativas oficiais. ${ }^{18}$

Na primeira publicação, vale ressaltar a inserção das biografias orientadas pelos prenomes das mulheres em vez dos nomes das famílias, pois pela história as negras e as indígenas não necessariamente possuem sobrenomes. Já na segunda, além dos dados pessoais das mulheres negras, foram narrados fatos e processos sociais inéditos não inclusos na malversada historiografia oficial.

Segundo diferentes autoras, tanto na América Latina e no Caribe ${ }^{19} \mathrm{Como} \mathrm{no} \mathrm{Brasil,}^{20}$ são visíveis as vivacidades do feminismo com sua trajetória de reformulações, conflitos e conquistas, trazendo novas personagens e realidades. A esse contexto Carneiro acrescenta a visão do enegrecimento do movimento feminista e da ampliação do protagonismo das mulheres negras como um aspecto altamente positivo.

Na região da América Latina e do Caribe, desde os idos anos 1970, foi realizado um total de 10 encontros feministas latino-americanos e do Caribe, e no Brasil 14 Encontros Nacionais Feministas - ENF. Por parte do Movimento Negro, em 2000, foi criada a Aliança de Líderes do Movimento de Afro-descendentes da América Latina e do Caribe, e no Brasil foram realizados dois Encontros Nacionais de Entidades Negras, em 1991 e 2001. Por parte das mulheres negras, foi criada a Rede de Mulheres Afro-latino-americanas, Afro-caribenhas e da Diáspora, e no Brasil foram realizados três Encontros Nacionais de Mulheres Negras ENMN, em 1988, 1992 e 2001.

\footnotetext{
15 Fátima OLIVEIRA, Matilde RIBEIRO e Nilza Iraci SILVA, 1995.

16 Schuma SCHUMAHER e Érico Vital BRAZIL, 2000, p. 10.

${ }_{17}$ Pela sua singularidade, este livro recebeu o Prêmio Jabuti 2008 como primeiro lugar na categoria Direitos Humanos.

${ }^{18}$ SCHUMAHER E BRAZIL, 2007, p. 9.

19 Sonia ALVAREZ, 1998.

${ }^{20}$ Sueli CARNEIRO, 2003; RIBEIRO, 2006; e Vera SOARES, 2004.
} 
É importante enfatizar que nos encontros feministas é expressivo o aumento do número de participantes na mesma proporção da presença efetiva de setores que antes não eram visíveis, como as mulheres oriundas da militância sindical, popular, negra e indígena. Também nos encontros do Movimento Negro e das Mulheres Negras são afirmadas a ação conjunta de combate ao racismo e à discriminação social e a ênfase às questões de gênero.

\title{
A inclusão de gênero e raça nas políticas públicas
}

\author{
Encontrei minhas origens/em velhos arquivos/[...] livros \\ encontrei/em malditos objetos/troncos e grilhetas \\ encontrei/em doces palavras/[...] cantos/em furiosos tambores/[...] ritos \\ encontrei minhas origens/na cor de minha pele/nos lanhos de minha alma \\ em mim/em minha gente escura/em meus heróis altivos/encontrei. ${ }^{21}$
}

O "encontro com as origens" é o que fortalece a compreensão sobre as possibilidades de incidência das questões de gênero e raça, avança-se em estudos e pesquisas no campo das políticas públicas e nas realidades sociais.

Leda Machado na pesquisa Deve gênero ser incluído nas políticas públicas nas áreas urbanas? partiu da hipótese de que:

a incorporação de gênero proporciona condições para que a realidade dos diferentes papéis desempenhados por homens e mulheres e conseqüentemente diferentes necessidades vivenciadas por eles, poderiam ser melhor apreendidas. Desta maneira, as políticas públicas teriam mais condições de atender às necessidades, já que elas seriam melhor entendidas. ${ }^{22}$

A autora analisa e compara vários programas ${ }^{23}$ de diferentes instituições nacionais e internacionais e verifica que a maioria deles, mesmo que às vezes se utiliza do conceito de gênero, não efetivam na prática a inclusão. Com isso, conclui:

Gênero não pode ser considerado uma panacéia para satisfação de diferentes necessidades, é um instrumento que possibilita o entendimento mais abrangente e complexo de como a sociedade é estruturada. Classe, etnia também são outros instrumentos que não podem ser menosprezados. O ideal seria que estes três fossem levados em consideração. ${ }^{24}$

Em 1999, Matilde Ribeiro concluiu a pesquisa Dimensões de gênero e raça no Orçamento Participativo em Santo André 1997-1999, que envolveu 22 conselheiras do Orçamento Participativo “ OP. No que se refere à questão de gênero, foi apontado:

as diferenças em relação à vida da mulher e do homem foram demarcadas pelas conselheiras, o que reafirmava o lugar social desfavorecido para as mulheres na estrutura organizativa do OP. Na justificativa das mulheres sobre o impedimento para sua participação, aparecem questões como: dificuldade de se manifestar em público, incompatibilidade dos horários de reuniões com os horários impostos pela vida doméstica

21 OLIVEIRA SILVEIRA, 1981.

${ }^{22}$ Leda M. V. MACHADO, 1996, p. 5.

${ }^{23}$ Programa de Renda Familiar Mínima - PRFM, da Prefeitura de Campinas; Programa de Núcleos Infantis de Cuidados Ninhos - PNICN, da Prefeitura de Campinas; National Liberacy Programme of Namibia - NLPN (Programa Nacional de Alfabetização da Namíbia); Lok Jumbish People's Moviment for Education for All, Rajasthan - PMEA (Programa de Educação para todos de Rajasthan); Projeto Disque, da Prefeitura de Santos; e Projeto México 70, da Prefeitura de São Vicente.

${ }^{24}$ MACHADO, 1996, p. 28. 
e pelo trabalho, além da falta de familiaridade com a vida políica, embora tivessem participação em movimentos sociais e políticos, em alguns casos ocupando funções de coordenação e/ou direção.

Quanto à identificação racial, ficou evidente o mito ou o terror de se pensar a cor como indicativo de diferença racial:

não chegava a ser um silêncio total sobre raça, mas, de certa forma, era uma questão de difícil abordagem. As conselheiras entrevistadas se posicionaram em duas vertentes quanto à existência ou não do racismo e/ou discriminação em relação aos negros: "Ainda é um grupo excluído na assistência social [...] ascensão social é difícil", versus o posicionamento de que não existe mais racismo: "Não vejo mais racismo, hoje, em Santo André. Há 20 anos era mais. Nos últimos 10 anos não existe mais". ${ }^{26}$

As conselheiras transmitiram com maior facilidade exemplos e questões relativas às necessidades das mulheres, embora nem todas tivessem feito afirmações positivas em relação à existência de necessidades específicas. Quanto à questão racial, as posições oscilaram entre umas que consideravam e outras que não consideravam a discriminação racial e étnica; em decorrência disto, a maioria não considerou a existência de necessidades específicas para negros e indígenas.

Tem ficado cada vez mais nítido que o olhar para a diversidade, e em especial para a inclusão da dimensão racial em pesquisas, estudos e políticas públicas, qualifica, cada vez mais, a agenda política nacional.

A área de pesquisa tem incidido nas ações da sociedade e dos governos, e viceversa. Portanto, o documento entregue ao Presidente da República, Fernando Henrique Cardoso, no momento da Marcha Zumbi dos Palmares, em 1995, impulsionou mudanças. As respostas governamentais em âmbito federal foram sendo construídas a partir de negociações entre movimento social e representantes da administração pública.

Foram criados dois espaços de formulação política - o Grupo de Trabalho Interministerial para a Valorização da População Negra " GTI População Negra, em 1996, e o Grupo de Trabalho para a Eliminação da Discriminação no Emprego e na Ocupação GTDEO, em 1997. Foi instalado o Programa Nacional de Direitos Humanos (I PNDH, em 1996; II PNHD, em 2002). E, em 2001, após a Conferência de Durban, foram iniciadas ações em vários ministérios, destacando-se a criação do Conselho Nacional de Combate à Discriminação " CNCD e do Programa Nacional de Ações Afirmativas, em 2002. No entanto, essas ações não significaram a efetivação de políticas continuadas, também não foi instituída uma coordenação entre as áreas citadas e nem um órgão responsável diretamente pela implementação de políticas de igualdade racial.

O governo do Presidente Luiz Inácio LULA da Silva, iniciado em janeiro de 2003, herda como tarefa a elaboração e a implementação do Programa Nacional de Ação pósDurban. Em 21 de março de 2003, foi criada a Secretaria Especial de Políticas de Promoção da lgualdade Racial " Seppir, um órgão com status de ministério e função de assessoramento ao Presidente da República. ${ }^{27}$ A partir daí foram criadas diretrizes governamentais visando à superação do combate ao racismo e à discriminação racial e étnica. Foram instituídos a

\footnotetext{
${ }^{25}$ RIBEIRO, 1999.

${ }^{26}$ RIBEIRO, 1999.

${ }^{27}$ A missão da Seppir é de: acompanhar e coordenar políticas de diferentes ministérios e de outros órgãos do Governo Federal para a promoção da igualdade racial; articular, promover e acompanhar a execução de diversos programas de cooperação com organismos públicos e privados, nacionais e internacionais; e acompanhar e promover o cumprimento de acordos e convenções internacionais assinadas pelo Brasil que digam respeito à promoção da igualdade racial e ao combate ao racismo.
} 
Política Nacional de Promoção da lgualdade Racial - PNPIR e também o Conselho Nacional de Promoção da Igualdade Racial - CNPIR, o que significou um novo marco regulatório para as ações do Governo Federal. Outro aspecto inédito da ação governamental na esfera social foi a inclusão da diretriz "redução das desigualdades raciais" no Plano Plurianual - PPA, ${ }^{28}$ nas versões de 2004-2007 e 2008-201 1.

Foram criados também outros órgãos com missão similar à Seppir, considerando o posicionamento de superação das desigualdades históricas: a Secretaria Especial de Políticas para as Mulheres - SPM, a Secretaria Especial dos Direitos Humanos - SEDH e a Secretaria Nacional de Juventude - SNJ.

Quanto às formas de gestão participativa, destaca-se a realização das conferências nacionais em diversas áreas (educação, saúde, meio ambiente, assistência social, direitos humanos, mulheres, entre outras). Entre 2003-2008, mais de 3,4 milhões de brasileiros participaram de 49 conferências nacionais, demonstrando um significativo salto de qualidade nas políticas públicas ao promoverem o controle social e a relação com os movimentos organizados, cidadãos e cidadãs.

Como parte dessa estratégia, foi realizada pela Seppir e o CNPIR a I Conferência Nacional de Promoção da lgualdade Racial - CONAPIR, em 1995. Essa conferência teve como tema "Estado e Sociedade construindo a Igualdade Racial" e mobilizou 95.573 participantes, configurando-se como instrumento de continuidade dos debates e das formulações conjuntas entre governo e sociedade civil.

A partir da implementação do Plano Nacional de Promoção da lgualdade Racial Planapir, reafirmam-se ações prioritárias em educação, saúde, segurança, trabalho e acesso a terra (expressas pela Agenda Social Quilombola como parte do Programa Brasil Quilombola).

Também, em 2004 e 2007, foram realizadas as Conferências Nacionais dos Direitos da Mulher - CNPM. A II CNPM aglutinou cerca de 200 mil pessoas, que participaram em todo o País das conferências municipais e estaduais e elegeram 2.700 delegadas/os para o evento nacional. Como resultado, o II Plano Nacional de Políticas para as Mulheres PNPM é orientado pelas seguintes diretrizes gerais: autonomia econômica e igualdade no mundo do trabalho, com inclusão social; educação inclusiva, não sexista, não racista, não homofóbica e não lesbofóbica; saúde das mulheres, direitos sexuais e direitos reprodutivos; enfrentamento de todas as formas de violência contra as mulheres; participação das mulheres nos espaços de poder e decisão; desenvolvimento sustentável no meio rural, na cidade e na floresta, com garantia de justiça ambiental, soberania e segurança alimentar; direito a terra, moradia digna e infra-estrutura social nos meios rural e urbano, considerando as comunidades tradicionais; cultura, comunicação e mídia igualitárias, democráticas e não discriminatórias; enfrentamento do racismo, sexismo e lesbofobia; e enfrentamento das desigualdades geracionais que atingem as mulheres, com especial atenção às jovens e idosas.

Diante desse mosaico de diretrizes e ações, cabe ressaltar a Lei Maria da Penha e o Pacto Nacional pelo Enfrentamento à Violência contra a Mulher.

É importante destacar que as mulheres negras incidiram na elaboração do capítulo "Enfrentamento do racismo, sexismo e lesbofobia", no II PNPM. O conteúdo desse capítulo apresenta a necessidade urgente de assegurar a incorporação da perspectiva de raça/ etnia e a orientação sexual nas políticas públicas direcionadas às mulheres.

\footnotetext{
${ }^{28}$ Plano Plurianual é o instrumento de planejamento de médio prazo do Governo Federal que estabelece, de forma descentralizada, diretrizes, objetivos e metas da Administração Pública Federal no período de quatro anos, promovendo a identificação clara dos objetivos e das prioridades do governo.
} 
Essa incidência das mulheres negras foi demarcada durante os eventos nacionais, mas também no processo preparatório, como se pode verificar nos documentos Mulheres negras brasileiras na II Conferência Nacional de Políticas para Mulheres ${ }^{29}$ e também no Dossiê sobre a situação das mulheres negras brasileiras. ${ }^{30}$

Sem dúvida, está em curso a elaboração de propostas de políticas públicas que contribuam para a alteração do quadro da desigualdade racial e de gênero em âmbito nacional e internacional.

\title{
Os processos das conferências internacionais
}

\author{
No mapa das Antilhas \\ mares que se entulham de ilhas \\ Nas ilhas das Antilhas \\ Gente negra que pontilha. ${ }^{31}$
}

Os negros estão nas "Antilhas", estão no mundo, e infelizmente as desigualdades também. Por isso, com o Ciclo das Conferências Mundiais promovido pela Organização das Nações Unidas " ONU, nos anos 1990, houve o estímulo aos debates e às formulações nas esferas da vida social econômica, política e cultural. Foram base para essas conferências a Declaração Universal dos Direitos Humanos, adotada em Paris/França, em 10 de dezembro de 1948, em conjunto com a Convenção Internacional sobre a Eliminação de todas as Formas de Discriminação Racial - ICERD, em 1965, e a Convenção sobre a Eliminação de todas as Formas de Discriminação contra a Mulher-CEDAW, em 1979, entre outros. ${ }^{32}$

Rita Laura Segato, ${ }^{33}$ no documento Mulher negra = sujeito de direitos e as convenções para a eliminação da discriminação, apresenta um importante cotejo entre ICERD e CEDAW, buscando disponibilizar uma análise dos pontos comuns e diferentes entre as duas convenções, como apoio à prática dos setores governamentais e não-governamentais. Parte-se do pressuposto de que a incidência de duplo preconceito e discriminação de gênero e de raça afeta os direitos humanos de maneira geral, e em particular as mulheres negras.

Considerando esses pressupostos, a Declaração e Programa de Ação de Beijing diagnostica e aponta medidas para alteração das condições de vida, reafirmando compromissos em prol dos direitos humanos das mulheres, combinados com a necessidade de superação das injustiças sociais que abatem sobre a população não branca, discriminada pelo racismo.

A Conferência de Durban teve como slogan "Unidos para combater o Racismo: Igualdade, Justiça e Dignidade" e foi conectada à agenda "2001 - Ano Internacional de Mobilização contra o Racismo, a Discriminação Racial, a Xenofobia e as Formas Conexas

\footnotetext{
${ }^{29}$ Produto da reunião ocorrida no período de 16 e 17 de agosto de 2007, com a participação de representantes de diferentes regiões e movimentos do País, com o apoio do Unifem e da Agência Espanhola de Cooperação Internacional - AECl.

${ }^{30}$ Elaborado pela Articulação de Organizações de Mulheres Negras Brasileiras - AMNB (com o apoio da Fundação Ford e do Unifem) e apresentado em 17 de julho de 2008 na audiência da Comissão de Direitos Humanos da Organização dos Estados Americanos, em Washington/EUA.

31 OLIVEIRA SILVEIRA, 1981.

${ }^{32}$ Além das conferências destacadas neste artigo, foram realizadas a Conferência Mundial sobre Meio Ambiente e Desenvolvimento (Brasil/Rio de Janeiro, 1992); a Conferência Mundial sobre os Direitos Humanos (Áustria/Viena, 1993); a Conferência Internacional sobre População e Desenvolvimento (Egito/Cairo, 1994); a Cúpula Mundial de Desenvolvimento Social (Dinamarca/Copenhague, 1995); a Conferência Mundial sobre Assentamentos Humanos - Habitat II (Turquia/lstambul, 1996); e a Cúpula Mundial de Alimentação (Itália/Roma, 1996).

${ }^{33}$ Rita Laura SEGATO, 2006.
} 
de Intolerância". O início dessa conferência intensificou-se em 2000, o Comitê Preparatório para a Conferência Mundial e os Grupos de Trabalho registraram muitas reuniões preparatórias.

Destacam-se as conferências regionais preparatórias - a européia (Estrasburgo) no período de 11 a 13 de outubro de 2000, a das Américas (Santiago) no período de 5 a 7 de dezembro de 2000, a africana (Dakar) no período de 22 a 24 de janeiro de 2001 e a asiática (Teerã) no período de 19 a 21 de fevereiro de 2001. O Fórum Mundial das Organizações Não-Governamentais ocorreu em Durban, no período de 28 de agosto a 3 de setembro de 2001, contando com aproximadamente 7.000 representantes de cerca de 3.000 ONGs.

Em particular na região das Américas, os resultados da Conferência Cidadã ${ }^{34}$ (sociedade civil) e da Conferência de Santiago (oficial) afunilam-se na Declaração e Plano de Ação de Santiago, ${ }^{35}$ que antecede e incide na elaboração da Declaração e Programa de Ação de Durban. Nesse documento global foi apontada a necessidade de superação: mulheres;

a) das múltiplas formas de discriminação que podem afetar mais diretamente as

b) das desigualdades geradas pelas condições de raça, cor, linguagem ou origem nacional ou étnica;

c) dos motivos conexos, como o sexo, o idioma, a religião, as opiniões políiticas ou de outra índole; $\mathrm{e}$

d) das barreiras por origem social, situação econômica, nascimento ou outra condição. Foram apresentadas, também, formulações voltadas às crianças e aos jovens, em especial às meninas por sua situação de vulnerabilidade, assim como a reafirmação sobre o direito dos povos vitimados à reparação.

Rosana Heringer ${ }^{36}$ e Sueli Carneiro ${ }^{37}$ enaltecem as formulações que visam à eliminação da desigualdade racial e de gênero nas metas indicadas pela Conferência de Durban no que diz respeito às ações afirmativas e às políticas universais. Heringer afirma que uma das atividades mais interessantes do Fórum de ONGs foi o dia organizado pela Comissão de Gênero:

com a participação de mais de 500 mulheres ao longo do dia [...] cumpriu sua missão de servir como um espaço de encontro de mulheres de todas as partes do mundo, dando sua contribuição a luta anti-racista. Após mais de 10 horas de trabalho, chegouse a um elenco de análises e propostas destinadas a subsidiar a declaração final. ${ }^{3 \mathrm{~g}}$

Ficam então sinalizados os caminhos para a ação dos governos e da sociedade civil, que, de maneira assertiva, pelas vozes dos movimentos sociais, em especial o negro e o feminista, com o protagonismo das mulheres negras, devem seguir o caminho da superação das desigualdades. Esses devem atentar-se para a questão primordial de que o racismo e a escravidão configuram-se como crimes contra a humanidade.

\footnotetext{
${ }^{34}$ A Conferência Cidadã contra o Racismo, a Xenofobia, a Intolerância e a Discriminação - Foro de ONGs e Organizações da Sociedade Civil das Américas " também foi realizada em Santiago/Chile, no período de 2 a 3 de dezembro de 2000.

${ }^{35}$ Neste documento é fortalecida a visão de que a América constituiu-se como espaço de convivência de distintas raças e culturas que se somaram aos povos originários, valorizando a característica de ser multicultural, multiétnica, multilíngüe e plurirreligiosa. Portanto, apresenta uma riquíssima composição dos agrupamentos humanos.

${ }^{36}$ Rosana HERINGER, 2001.

37 CARNEIRO, 2002.

${ }^{38}$ HERINGER, 2001.
} 


\section{O pós-Durban, a ação e o monitoramento}

eu bato contra o muro duro não desisto de forçá-lo

hei de encontrar um furo

por onde ultrapassá-lo. ${ }^{39}$

Aos poucos, rompem-se "muros", e, após a Conferência de Durban, uma das primeiras análises oficiais dos processos de implementação da Declaração e Programa de Ação de Durban foi elaborada por Álvaro Bello, ${ }^{40}$ sob coordenação do Alto Comissariado das Nações Unidas para os Direitos Humanos. O autor identifica um processo crescente e inovador que, ainda com fragilidades, é bastante promissor. Nesse sentido, foram apresentados 17 desafios a serem enfrentados por várias instituições que vão na linha do fortalecimento dos compromissos estabelecidos pela Conferência de Durban, constando a ênfase na necessidade de incorporação da perspectiva de gênero no combate ao racismo e à discriminação, especialmente no que se refere à situação das mulheres.

Constata-se que a principal novidade no processo pós-Durban tem sido a criação de instâncias voltadas ao tratamento das questões raciais e de discriminação racial e étnica em 16 países - Argentina, Bolívia, Brasil, Canadá, Chile, Colômbia, Costa Rica, Equador, Estados Unidos, Guatemala, Honduras, México, Panamá, Peru, Uruguai e Venezuela. Essa é uma forma de sedimentação das proposições elaboradas pela sociedade civil, em negociação com governos, o que põe em prática a indicação de que os Estados necessitam redobrar esforços para avançar de maneira mais decisiva na implementação dos planos de ação, envolvendo os integrantes da sociedade civil, as instituições nacionais e internacionais.

Um grande número de agências do Sistema ONU no Brasil incorporam, a partir de 2005, o Grupo de Trabalho Interagencial de Gênero e Raça da ONU, coordenado pelo Unifem. Esse GT tem desempenhado importante papel no apoio ao desenvolvimento das atividades organizadas pelo governo e pela sociedade civil, como estratégias para superação do racismo, das discriminações raciais e étnicas, e das desigualdades de gênero, considerando a realidade nacional e internacional. ${ }^{41}$

Também, no Mercosul, junto à Reunião de Altas Autoridades em Direitos Humanos e Chancelarias do Mercosul e Estados Associados " RAADH, ${ }^{42}$ foi criado o Grupo de Trabalho sobre a lgualdade Racial (em dezembro de 2006), composto de 10 países. Esse GT impulsiona o desenvolvimento de ações governamentais e multilaterais para a promoção da igualdade racial, contemplando afrodescendentes e indígenas. A agenda futura prevê os compromissos com a revisão de Durban e a elaboração da Convenção Interamericana para a Eliminação de todas as Formas de Discriminação Racial, assim como com as ações compartilhadas entre sociedade civil e governos.

Consolidando mais um ciclo organizativo na região, realizou-se no período de 26 a 28 de julho de 2006, em Brasília, a Conferência Regional das Américas sobre os Avanços e Desafios do Plano de Ação contra o Racismo, a Discriminação Racial, a Xenofobia e as

\footnotetext{
39 OLIVEIRA SILVEIRA apud COLIMA, 1982.

40 Álvaro BELLO, 2006.

${ }^{41}$ SECRETARIA ESPECIAL DE POLÍTICAS DE PROMOÇÃO DA IGUALDADE RACIAL, 2007.

${ }^{42}$ Por parte do Brasil, a RAADH é coordenada pela Secretaria Especial dos Direitos Humanos, tendo a Seppir como colaboradora.
} 
Intolerâncias Correlatas - CRA. ${ }^{43}$ Esse evento foi coordenado pelos governos do Brasil e do Chile, em parceria com o Comitê Internacional ${ }^{44}$ e com o apoio do Alto Comissariado das Nações Unidas para os Direitos Humanos.

A CRA contou com a participação de representantes governamentais e nãogovernamentais de 21 países. O Relatório da Conferência Regional das Américas sobre os Avanços e Desafios do Plano de Ação contra o Racismo, a Discriminação Racial, a Xenofobia e as Intolerância Correlatas enfatiza a importância de se desenvolverem políticas públicas eficazes no combate a toda sorte de discriminação:

[...] reconhecendo os avanços obtidos para a superação das desigualdades, identificando projetos inovadores, cumprindo assim, a função essencial de promover um diálogo interativo entre os principais protagonistas envolvidos nessa agenda, assim como um impulso aos consensos já alcançados, e fortalecer a promoção da diversidade, da igualdade, da paz e da democracia nas Américas. ${ }^{45}$

A experiência inovadora de realização de um evento conjunto entre governo e sociedade civil, tendo por base a agenda global, apresentou riquezas e desafios e obteve como resultado final um documento unificado reconhecido pelo Alto Comissariado das Nações Unidas para os Direitos Humanos. Foi, sem dúvida, uma oportunidade ímpar para que os Estados e os membros da sociedade civil da região reafirmassem seus objetivos, a partir de negociações que resultaram em uma agenda comum, tendo como marco o compromisso de continuidade do monitoramento da implementação do Programa de Ação de Durban.

Novamente, em 2008, o Brasil foi palco de mais uma rodada de debates e formulações, o que proporcionou a realização do Fórum da Sociedade Civil das Américas para Avaliação dos Resultados de Durban, ${ }^{46}$ no período de 13 a 15 de julho de 2008, e da Conferência da América Latina e do Caribe, Preparatória à Conferência de Exame de Durban, no período de 17 a 19 de julho de 2008, esta segunda com caráter oficial, coordenada pelo Alto Comissariado das Nações Unidas para os Direitos Humanos.

Na Declaração da Sociedade Civil das Américas ${ }^{47}$ e no Documento Final da Conferência Regional da América Latina e do Caribe, Preparatória à Conferência de Exame de Durban, são reconhecidos os esforços dos Estados da região no desenvolvimento de

\footnotetext{
${ }^{43}$ As diversas ações da sociedade civil resultaram na criação em 2004 do Comitê de Iniciativas Santiago + 5 - composto das organizações: Aliança de Líderes do Movimento de Afrodescendentes da América Latina e do Caribe (Mundo Afro/Uruguai); Geledés Instituto da Mulher Negra e Centro de Articulação de Populações Marginalizadas (Brasil); Fundación Ideas (Chile); Human Rights Internet (Canadá); Foro de Diplomacia Ciudadana de América Latina y Caribe (Argentina); e Instituto Interamericano de Derechos Humanos (Costa Rica). Esse comitê impulsionou a realização da Pré-conferência das Américas, no período de 10 a 12 de agosto de 2005 , em Santiago/Chile. O registro desse evento está no documento marco - Pré-conferência Santiago + 5 contra o Racismo, a Xenofobia, a Discriminação e as Formas Conexas de Intolerância -, que reflete um balanço positivo das ações na região.

${ }^{44} \mathrm{O}$ Comitê Internacional foi formado por representantes das seguintes organizações: African Canadian Legal Clinic, Human Rights Internet, Comitê Intertribal, New Constituency Development and Health Disparities Initiatives, Centro de Culturas Indígenas del Perú, Centro de Articulação de Populações Marginalizadas CEAP, Escuela Graduada de Administracion Publica Universidad de Puerto Rico, Organizacion de Desarrollo Etnico Comunitario - ODECO, Mundo Afro, Instituto Interamericano de Direitos Humanos, Geledés Instituto da Mulher Negra e Fundação Ideas (Chile). Participaram de maneira individual Sergia Galvan e Ann Mckinley.

${ }^{45}$ CONFERÊNCIA REGIONAL DAS AMÉRICAS, 2006, p. 21.

${ }^{46}$ Coordenado pelo Comitê Internacional da Sociedade Civil, constituído desde 2005, com o apoio do governo brasileiro.

${ }^{47}$ Fórum da Sociedade Civil das Américas para Avaliação dos Resultados de Durban. Documento Preliminar, de 13 a 15 de junho de 2008. Brasília, 2008.
} 
políticas visando à superação do racismo e das discriminações raciais e étnicas. O documento da sociedade civil enfatiza a necessidade de maior institucionalidade e aplicação de recursos orçamentários necessários para implementar os compromissos estabelecidos e a importância da efetivação de condições para uma participação paritária da sociedade civil no desenvolvimento e na implementação das políticas públicas. No documento oficial, afirmam-se os compromissos com a superação do racismo e da discriminação racial e étnica, e enfatiza-se a necessidade de avanço na inclusão de um enfoque de gênero de maneira prioritária nas agendas de trabalho, visando ao enfrentamento do fenômeno da discriminação múltipla e agravada contra as mulheres.

No processo regional pós-Durban, as mulheres expressaram formas específicas de organização. No período de 24 e 25 de julho de 2006, compuseram o Comitê Internacional da Conferência Regional das Américas e realizaram o seminário Diálogo entre as Mulheres das Américas contra o Racismo e todas as Formas de Discriminação; ${ }^{48}$ e, em 2008 , reapresentam suas demandas, a partir da Declaração das Mulheres, no Fórum da Sociedade Civil das Américas para Avaliação dos resultados de Durban. ${ }^{49}$

Em ambas as situações, no contexto das conferências regionais de monitoramento da implementação da Declaração e Programa de Ação de Durban, as mulheres negras contribuíram com formulações para deliberações que apontam a necessidade de os governos federais ampliarem políticas públicas visando à efetivação da inclusão das populações negra e indígena e de outros grupos sociais vulneráveis, destacando as mulheres negras e indígenas.

\title{
A abolição inacabada e as expectativas de futuro
}

\author{
Treze de maio traição/liberdade sem asas \\ Treze de maio - já dia 14/o Y da encruzilhada: seguir, banzar, voltar? \\ o que temos nós lutamos/para sobreviver/e também somos esta pátria \\ em nós ela está plantada/nela crispamos raízes/de enxerto mas sentimos \\ e mutuamente arraigamos/quem sabe só com isto: \\ que ela é nossa também, sem favor/e sem pedir respiramos seu ar \\ tapamos-destapamos horizontes. \\ e então vamos rasgar/a máscara do treze/para arrancar a dívida real \\ com nossas próprias mãos. ${ }^{50}$
}

"Banzo - saudade negra", energias para mudanças de um destino que os negros não traçaram, por outro lado, construiu-se a resistência. Por isso, no Centenário da Abolição, como uma revisão histórica, Abdias do Nascimento ${ }^{51}$ argumentou:

como esquecer que a República, logo após a abolição, cassou ao ex-escravo seu direito de votar, inscrevendo na Constituição que só aos alfabetizados se concedia a prerrogativa desse direito cívico? Como esquecer que, após nosso banimento do trabalho livre e assalariado, o código penal de 1890 veio definir o delito de vadiagem para aqueles que não tinham trabalho, como mais uma forma de manter o negro à mercê

\footnotetext{
${ }^{48}$ Declaração das Mulheres "Diálogo entre as Mulheres das Américas contra o Racismo e todas as Formas de Discriminação" no seminário organizado pelas mulheres do Comitê Internacional da Conferência das Américas, que ocorreu em 24 e 25 de julho de 2006, em Brasília.

${ }^{49}$ Declaração das Mulheres, no Fórum da Sociedade Civil das Américas para Avaliação dos Resultados de Durban, que ocorreu de 13 a 15 de junho de 2008, em Brasília.

${ }^{50}$ OLIVEIRA SILVEIRA, 1987.

${ }^{51}$ Com 95 anos, Abdias do Nascimento é um dos mais velhos militantes vivos. Consagrou-se pela defesa intransigente do respeito à dignidade humana em sua múltipla militância, no Movimento Negro, como parlamentar, artista e intelectual.
} 
do arbítrio e da violência policiais? Ainda mais, definiram como crime a capoeira, a própria expressão cultural africana. Reprimiram com toda a violência do estado policial as religiões afro-brasileiras, cujos terreiros se viram duramente invadidos, os fiéis e os sacerdotes presos, pelo crime de praticar sua fé religiosa. Temos vivido num estado de terror: desde 1890, o negro vem sendo o preso político mais ignorado desse País. ${ }^{52}$

No que diz respeito aos 120 anos de abolição da escravidão, embora a onda comemorativa tenha sido bem menor do que no Centenário da Abolição, permanecem as críticas:

É engraçado que um silêncio gritante se fez presente nesses 119 anos. Tem gente que não gosta desse assunto. Tem gente que não quer que falemos que ainda há muita discriminação, que há muito preconceito. Sem dúvida nós avançamos, mas algo está errado. A maioria do nosso povo negro permanece morando em favelas, trabalhando nas casas como domésticos, fora das universidades, o Parlamento, do Executivo, e, dos primeiros escalões das áreas públicas e privada, a não ser como raras exceções. É esse preconceito velado que queremos eliminar. ${ }^{53}$

A tensão na sociedade brasileira era algo constante nas fazendas, nas casas-grande, mas também nas senzalas e nos quilombos, nas irmandades, nas cidades do império [na época da escravidão]. [...] Não podemos nos esquivar de um fato a liberdade foi conquistada formalmente à 120 anos, mas agora o próximo passo dos descendentes daqueles que tanto lutaram tem que ser levado a frente, seja para a implementação de políticas públicas, seja para a aquisição de seu sonho à época, ou seja, a conquista da terra. ${ }^{54}$

Assim como Nascimento, Paim e Fonseca nos remetem a uma história passada que tem muito reflexo em nosso cotidiano e com isso nos faz pensar sobre as formulações e as ações do presente.

Tendo como referência essas análises, o Movimento Negro buscou trazer a público suas reivindicações e críticas aos setores que expressavam interesse apenas em comemorar pura e simplesmente um fato que demarca, ainda na atualidade, uma realidade dura e contraditória.

Do ponto de vista legal, após a Lei Áurea, o primeiro texto que buscou combater a discriminação racial foi a Lei n. 1.390/51 - Lei Afonso Arinos. Posteriormente, a Constituição Cidadã assegura que "a prática do racismo constitui crime inafiançável e imprescritível, sujeito à pena de reclusão nos termos da lei" ${ }^{55}$ (artigo $5^{\circ}$ ) e prevê o reconhecimento e o direito dos remanescentes das comunidades de quilombos às suas terras (artigo 68 - Ato das Disposições Transitórias). A Lei n. 7.716 de 5 de janeiro de 1989 "Lei Caó " passou a definir os crimes resultantes de preconceito de raça ou de cor, tipificando condutas que abstêm acesso a serviços, cargos e empregos.

Recentemente, em 13 de maio de 2008, foi aprovado no Plenário da Câmara dos Deputados o Projeto de Lei n. 7.198/02 do Senado Federal, que concede anistia post mortem a João Cândido Felisberto, o Almirante Negro, líder da Revolta da Chibata, ${ }^{56}$ e aos demais participantes do movimento. Esse projeto retornou ao Senado e em 23 de julho de 2008 foi sancionado pelo Executivo.

\footnotetext{
52 NASCIMENTO, 1988.

53 Paulo PAIM, 2007.

${ }^{54}$ Dagoberto José FONSECA, 2008.

55 BRASIL, 1988.

${ }^{56} \mathrm{~A}$ revolta aconteceu em protesto contra os castigos físicos que eram impostos pela Marinha do Brasil no início do século passado. O objetivo do projeto é de restaurar os direitos que foram assegurados aos revoltosos pelo Decreto n. 2.280, de 1910.
} 
Em 20 de novembro de 2008 foi aprovado na Câmara Federal o Projeto de Lei n. 73/ 99 , que reserva $50 \%$ das vagas das universidades públicas a alunos que cursaram integralmente o ensino médio em escolas públicas, respeitando o percentual de negros e indígenas em cada Unidade da Federação. Esse projeto seguirá para aprovação no Senado Federal.

Tramita desde o final dos anos 1990 no Congresso Nacional o Projeto de Lei Estatuto da Igualdade Racial, que prevê ações afirmativas visando superar as desigualdades fundadas em raça/cor/etnia. Esse projeto aprovado no Senado seguiu em 29 de novembro de 2005 para a devida aprovação na Câmara dos Deputados.

Não é exagero afirmar que, no plano formal, as leis cumprem um papel importante no combate às práticas de discriminação racial, com isso se reforça a perspectiva de aprovação do Estatuto da Igualdade Racial.

É fato que muitas coisas mudaram nessas duas últimas décadas, chegamos aos 120 anos da abolição com experiências efetivas de implementação de políticas públicas e leis buscando responder ao nefasto quadro de discriminação e racismo, no entanto, a realidade é de uma abolição inacabada. Para reversão desse quadro, os desafios são inúmeros.

a) O governo brasileiro vive um momento ímpar no que diz respeito à efetivação de políticas de igualdade racial. Qual a negociação/mediação planejada pelo movimento social para garantir aceleração na implementação das políticas públicas?

b) Está em processo de organização a II Conferência Nacional de Promoção da Igualdade Racial, a ser realizada em 2009. Quais as amarrações para fortalecimento de relações entre sociedade civil e governo, considerando o Projeto Nacional para Superação do Racismo e do Machismo?

c) O Movimento Negro desenvolve as ações relativas ao Congresso Nacional de Negras e Negros do Brasil, que está previsto para 2009. Quais as formas organizativas que esse movimento apresentará para a conquista de melhores condições de vida para a população negra, e para as mulheres negras em particular?

d) Em 2009 será realizado mais um Encontro Nacional Feminista (em Pernambuco) e o XI Encontro Feminista Latino-americano e do Caribe (na cidade do México). Qual o salto teórico e organizativo planejado pelas mulheres negras brasileiras e da região no interior da organização feminista?

e) Está em fase de elaboração o projeto da Convenção Interamericana para a Eliminação de todas as Formas de Discriminação Racial, tendo por base a ICERD. Em que medida essa convenção vai responder à realidade da região do ponto de vista da sua diversidade e necessidades específicas para superação das fortes desigualdades e iniqüidades existentes na região?

f) Será realizada em 2009, em Genebra, a Conferência de Revisão de Durban. Até que ponto novas estratégias serão definidas para acelerar o processo das políticas de superação do racismo, do machismo e das demais questões que ofendem os direitos humanos?

g) Muitos projetos de lei na área dos direitos humanos e da justiça racial tramitam no Congresso Nacional. Como garantir a ampliação da dimensão das leis, sobretudo, no que diz respeito à penalização das práticas de racismo?

h) Por fim, quais as novas estratégias do movimento social e dos governos para aprofundar o diálogo e a intervenção entre as questões de gênero e raça, fazendo valer a perspectiva de interseccionalidade e da democracia? 


\section{Considerações finais}

Diante de tão rica construção, é possível dizer que as organizações de mulheres negras fizeram valer seu propósito de adquirir "maioridade política" diante dos movimentos feminista e de negro, de instituições públicas e privadas e da sociedade em geral. Com isso, demonstraram a disponibilidade de construção de seus próprios caminhos.

No que se refere à relação institucional, com Estados e órgãos multilaterais, em geral, os interesses entre os movimentos sociais, os governos e as agências multilaterais não são exatamente os mesmos, misturam-se dilemas e conflitos em meio a proposições de mudanças sociais. Um bom exemplo são as conferências mundiais, que partem da necessidade de negociação e mediação de agendas políticas, buscando ter como resultado proposições de ações visando à construção de uma agenda comum.

Pela complexidade, essa realidade deve despertar os agentes políticos, sobretudo os movimentos sociais, para as profundidades e as concretudes das políticas públicas que garantam os princípios de democracia, diversidade e direitos.

O caminho apresenta-se como promissor, a abolição é inacabada, mas podemos desenhar um futuro inclusivo. Espera-se a efetivação cada vez mais de diálogos críticos e ações conjuntas entre os diversos setores da sociedade civil, e destes com os governos, com a academia, com os órgãos multilaterais, entre outros. Com essa dinâmica é possível estabelecer parâmetros de análise mais próximos da realidade e, freqüentemente, remodelar a prática institucional.

A agenda política é extremamente complexa, e, justamente por isso, o trabalho é desafiante, fascinante e incansável, como a própria vida das mulheres, dos negros e das mulheres negras, em particular.

\section{Referências bibliográficas}

ALVAREZ, Sonia. "Feminismos latinoamericanos: reflexiones teóricas y perspectivas comparativas". In: RíOS, Marcela Tobar (Org.). Reflexiones teóricas y comparativas sobre los feminismos en Chile y América Latina. Santiago: Notas del Conversatorio, 1998. p. 4-22.

ARTICULAÇÃO DE ORGANIZAÇÕES DE MULHERES NEGRAS BRASILEIRAS. Dossiê sobre a situação das mulheres negras brasileiras. São Paulo, 2007.

BAIRROS, Luiza. "Apresentação". Revista Estudos Feministas, Florianópolis, Universidade Federal de Santa Catarina, Centro de Filosofia e Ciências Humanas e Centro de Comunicação e Expressão, v.10, n. 1, p. 169-170, 2002. Dossiê III Conferência Mundial contra o Racismo.

BELLO, Álvaro. Revisão e valoração da implementação da Declaração e Programa de Ação da Conferência Mundial contra o Racismo, a Discriminação Racial, a Xenofobia e as Formas Conexas de Intolerância nas Américas. Genebra, 20 jul. 2006. Oficina do Alto Comissariado das Nações Unidas para os Direitos Humanos. Documento de Trabalho n. 5.

BRASIL. Constituição da República Federativa do Brasil. Brasília, 1988.

. Lei n. 11.340/06. Sobre violência doméstica e familiar contra a mulher. Brasília, 2006.

CARNEIRO, Sueli. "A batalha de Durban". Revista Estudos Feministas, Florianópolis, Universidade Federal de Santa Catarina, Centro de Filosofia e Ciências Humanas e Centro de Comunicação e Expressão, v. 10, n. 1, p. 2.009-2.014, 2002.

. "Enegrecer o feminismo: a situação da mulher negra na América Latina a partir de uma perspectiva de gênero". In: ASHOKA EMPREENDIMENTOS SOCIAIS; TAKANO CIDADANIA (Orgs.). Racismos contemporâneos. Rio de Janeiro: Takano Editora, 2003. p. 49-58. 
COLIMA, Paulo (Org.). Antologia contemporânea da poesia negra brasileira. São Paulo: Global Editora, 1982.

CONFERÊNCIA DA AMÉRICA LATINA E DO CARIBE. Preparatória à Conferência do Exame de Durban (17 a 19/06/08). ONU. Brasília, 2008. Documento Final.

CONFERÊNCIA NACIONAL DE PROMOÇÃO DA IGUALDADE RACIAL. Conapir. Brasília, Seppir: 2006. Relatório Final. Disponível em: http://www.planalto.gov.br/seppir/publicações/ relatorio_final_conapir.pdf. Acesso em: 3 nov. 2006.

CONFERÊNCIA NACIONAL DE POLÍTICAS PARA MULHERES. Mulheres negras brasileiras. Brasília, ago. 2007.

CONFERÊNCIA REGIONAL DAS AMÉRICAS. Preparativos para a Conferência Mundial contra o Racismo, a Discriminação Racial, a Xenofobia e as Formas Conexas de Intolerância (05 a 07/12/2000). Santiago/Chile, 2000.

. Avanços e Desafios do Plano de Ação contra o Racimo, Discriminação Racial, Xenofobia e Intolerâncias Correlatas. Brasília, Seppir, 2006. Relatório.

DECLARAÇÃO DA IV CONFERÊNCIA MUNDIAL SOBRE AS MULHERES. ONU. Beijing'95. Disponível em: http://www.dhnet.org.br/direitos/sip/onu/doc/pequim95.htm. Acesso em: 6 ago. 2008.

DECLARAÇÃO E PROGRAMA DE AÇÃO DE DURBAN. III Conferência Mundial contra o Racismo, a Discriminação Racial, a Xenofobia e as Formas Conexas de Intolerância. ONU. Nova lorque, 2002.

FONSECA, Dagoberto José. 13 de maio de 1888, 13 de maio de 2008: um aniversário de 120 anos. Disponível em: http://120cartas.ig.com.br/wp/13-de-maio-de-1888-13-demaio-de-2008-um-aniversario-de-120-anos/. Acesso em: set. 2008.

GONZALES, Lélia; HASEMBALG, Carlos. Lugar de negro. Rio de Janeiro: Marco Zero, 1982.

HERINGER, Rosana. "Durban é só o começo". Carta da CEPIA, Rio de Janeiro, n. 9, 2001.

INSTITUTO DE PESQUISA ECONÔMICA APLICADA; FUNDO DE DESENVOLVIMENTO DAS NAÇÕES UNIDAS PARA A MULHER; SECRETARIA ESPECIAL DE POLÍTICAS PARA AS MULHERES. Retrato das desigualdades - gênero e raça. 2007.

MACHADO, Leda M. V. Deve gênero ser incluído nas políticas públicas nas áreas urbanas? São Paulo: FGV, 1996. (Série Relatórios de Pesquisa).

MARCHA A BRASÍLIA. Por uma política de combate ao racismo e à desigualdade social. São Paulo: Coordenação Nacional de Entidades Negras, 1995.

NASCIMENTO, Abdias. 13 de maio: Dia de Denúncia contra o Racismo, Minas Gerais, n. 1.098, 7 maio 1988. (Suplemento Literário).

OLIVEIRA, Fátima; RIBEIRO, Matilde; SILVA, Nilza Iraci. "A mulher negra na década: a busca da autonomia". Caderno Gueledés, São Paulo, n. 5, 1995.

OLIVEIRA SILVEIRA. Roteiro dos Tantãs. Porto Alegre: Edição do Autor, 1981. Disponível em: http://www.portalafro.com.br/portoalegre/oliveira/conciencia.htm. Acesso em: nov. 2008. . Poema sobre Palmares. Porto Alegre: Edição do Autor, 1987.

Disponível em: http://www.portalafro.com.br/portoalegre/oliveira/movimentonegro.htm. Acesso em: nov. 2008.

OUTUBRO. 2 jan. 2009. Disponível em: http://outubro.blogspot.com/2009/01/oliveira-silveirapoeta-1941-2009.html. Acesso em: jan. 2009.

PAIM, Paulo. Lei Áurea: uma abolição não concluída. 13 maio 2007. Disponível em: http:// www.senado.gov.br/paulopaim/pages/imprensa/artigos/2007/13052007.htm. Acesso em: set. 2008.

RIBEIRO, Matilde. "Mulheres negras brasileiras, de Bertioga a Beijing". Revista Estudos Feministas, Rio de Janeiro, v. 3, n. 2, p. 446-57, 1995. Dossiê Mulheres Negras.

. Gênero e raça no Orçamento Participativo em Santo André 1997-1998. 1999. 
Dissertação (Mestrado) - Pontifícia Universidade Católica de São Paulo, São Paulo, 1999.

- "Relações raciais nas pesquisas e processos sociais - em busca de visibilidade para as mulheres negras". In: VENTURI, Gustavo; RECAMAN, Marisol; OLIVEIRA, Sueli. A mulher brasileira nos espaços público e privado. São Paulo: Fundação Perseu Abramo, 2004. p. 87-105.

. "O feminismo em novas rotas e visões". Revista Estudos Feministas, Florianópolis, Universidade Federal de Santa Catarina, Centro de Filosofia e Ciências Humanas e Centro de Comunicação e Expressão, v. 14, n. 3, p. 801-81 1, 2006.

. "Las mujeres negras em luta por sus derechos". Revista Nueva Sociedad, Buenos Aires, v. 218, nov./dez. 2008.

SCHUMAHER, Schuma; BRAZIL, Érico Vital (Orgs.). Dicionário mulheres do Brasil: de 1500 até a atualidade. Rio de Janeiro: Jorge Zahar, 2000.

. Mulheres negras do Brasil. Rio de Janeiro: Rede de Desenvolvimento Humano; São Paulo: Senac, 2007.

SECRETARIA ESPECIAL DE POLÍTICAS DE PROMOÇÃO DA IGUALDADE RACIAL. Relatório de Gestão (2003-2006). Brasília, Seppir, 2007.

SECRETARIA ESPECIAL DE POLÍTICAS PARA AS MULHERES. II Plano Nacional de Políticas para as Mulheres. Brasília, 2007.

SEGATO, Rita Laura. "Mulher negra = sujeito de direitos e as convenções para a eliminação da discriminação". Agende, Brasília, 2006.

SOARES, Vera. "O feminismo e o machismo na percepção das mulheres brasileiras". In: VENTURI, Gustavo; RECAMAN, Marisol; OLIVEIRA, Sueli. A mulher brasileira nos espaços público e privado. São Paulo: Fundação Perseu Abramo, 2004. p. 162-182.

[Recebido em novembro de 2008 e aceito para publicação em dezembro de 2008]

\section{Black Women: A Trajectory of Creativity, Determination and Organization}

Abstract: The article "Black Women: A Trajectory of Creativity, Determination and Organization" seeks to make a brief account, focusing on the process of black women's organization in dialogue with the following: the inclusion of gender and race in public policies; the holding of International Conferences - in particular, the World Conference on Women and the $3^{\text {rd }}$ World Conference against Racism, Racial Discrimination, Xenophobia and Related Intolerance; the Post-Durban period: action and monitoring; and the 120 years since the abolition of slavery. Lastly, some challenges are formulated as to the struggle for equality and social justice.

Key Words: Black Women; Feminist Movement; Black Movement; Organization of Black Women. 